BMJ Open Sport \& Exercise Medicine

\section{Severity and pattern of injuries caused by Swiss wrestling (Schwingen): first retrospective study at a level I University Emergency Department in Switzerland}

To cite: Maliachovas NK Klukowska-Rötzler J, Sauter TC, et al. Severity and pattern of injuries caused by Swiss wrestling (Schwingen): first retrospective study at a level I University Emergency Department in Switzerland. BMJ Open Sport \& Exercise Medicine 2018:4:e000270. doi:10.1136/ bmjsem-2017-000270

- Additional material is available in online only. To view please visit the journal online (http://dx.doi.org/10.1136/ bmjsem-2017-000270).

Accepted 27 November 2017

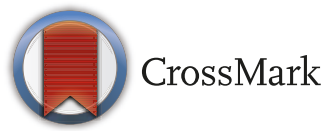

${ }^{1}$ Department of Emergency Medicine, University Hospital, Berne, Switzerland

${ }^{2}$ Department of Anaesthesiology, Muri Hospital, Muri, Switzerland

Correspondence to Dr Jolanta Klukowska-Rötzler; jolanta.klukowska-roetzler@ insel.ch

\section{ABSTRACT}

Background This article addresses typical injury patterns related to the traditional Swiss folk wrestling, 'Schwingen'. This is a fight between two competitors with its own rules, grips and throws. A variety of injuries have been occasionally reported. The aim of this study was to characterise all cases of Schwingen injuries treated in the University Hospital of Bern from January 2006 to July 2016.

Methods To assess the frequency, type and outcome of Schwingen injuries, database search was performed of all inpatient and outpatient cases related to Schwingen that were admitted to Bern University Hospital from January 2006 to December 2016.

Results A total of 32 such patients could be identified. Apart from a single woman, all patients were male. 31 of the 32 players were Swiss. One patient was admitted to the intermediate care unit, eight patients underwent surgery, two were hospitalised for further treatment and two were given a plaster. 17 other patients were given medications such as painkillers. One was dismissed without further treatment and another one left the hospital on his own. Typical injury patterns varied from simple lesions to distortions and fractures as well as head injuries and other neurological complications.

Conclusion The majority of injuries caused by Schwingen are not life threatening. Nevertheless, there is always the potential of head injuries and neurological deficits. Apart from the economic loss due to treatment costs and sick leave, these injuries can be disabling for life. It should therefore be obligatory for all players to evaluate preventive measures.

\section{INTRODUCTION}

Swiss wrestling ('Schwingen') is a traditional and popular Swiss national sport. ${ }^{1}$ As described by the Swiss Schwingen Federation (Eidgenössischer Schwingerverband), two strong wrestlers are pitted against each other trying to bring down the opponent with special swings and grips. ${ }^{23}$ It is a hard sport, sometimes regarded as a martial art, in which

\section{What are the new findings?}

This is the first in-depth assessment of characteristic Schwingen (Swiss wrestling) sport injury cases admitted to a level I trauma centre in Switzerland.

- No catastrophic injuries or fatalities were encountered in our study population.

- Fractures and sprains were the most frequent injury patterns.

- An effective precaution would be to provide all Schwingen players with protective gear such as headgear, mouthguards and knee pads.

- Maximising the ring area and using optimal material for its surface may also reduce injuries in Schwingen.

both strength and technique play crucial roles (figure 1A,B). During the year, many wrestling festivals take place all over Switzerland and every 3 years the new champion (Swiss Wrestling King-Schwingen König) is chosen.

Schwingen differs from competitive wrestling in many respects. It is practised on sawdust, most of the grips are fixed and the wrestlers wear jerseys or shirts and long trousers, over which short wrestling breeches made of jute are worn. Originally only a few throws were in use but current wrestling manuals describe around 100 different throws. ${ }^{45}$ Each bout lasts 5 min. ${ }^{6}$ It is ended either when time runs out or when a wrestler touches the ground with his back, either completely or simultaneously at the level of the middle of both shoulder blades, which should lie within the circle of sawdust. ${ }^{7}$ In the case of a 'set gear', the more active wrestler is the winner. There are no weight classes or any other categories. Schwingers are usually large men, over $180 \mathrm{~cm}$ tall and weighing in excess of $100 \mathrm{~kg}$, mostly craftsmen from traditional 


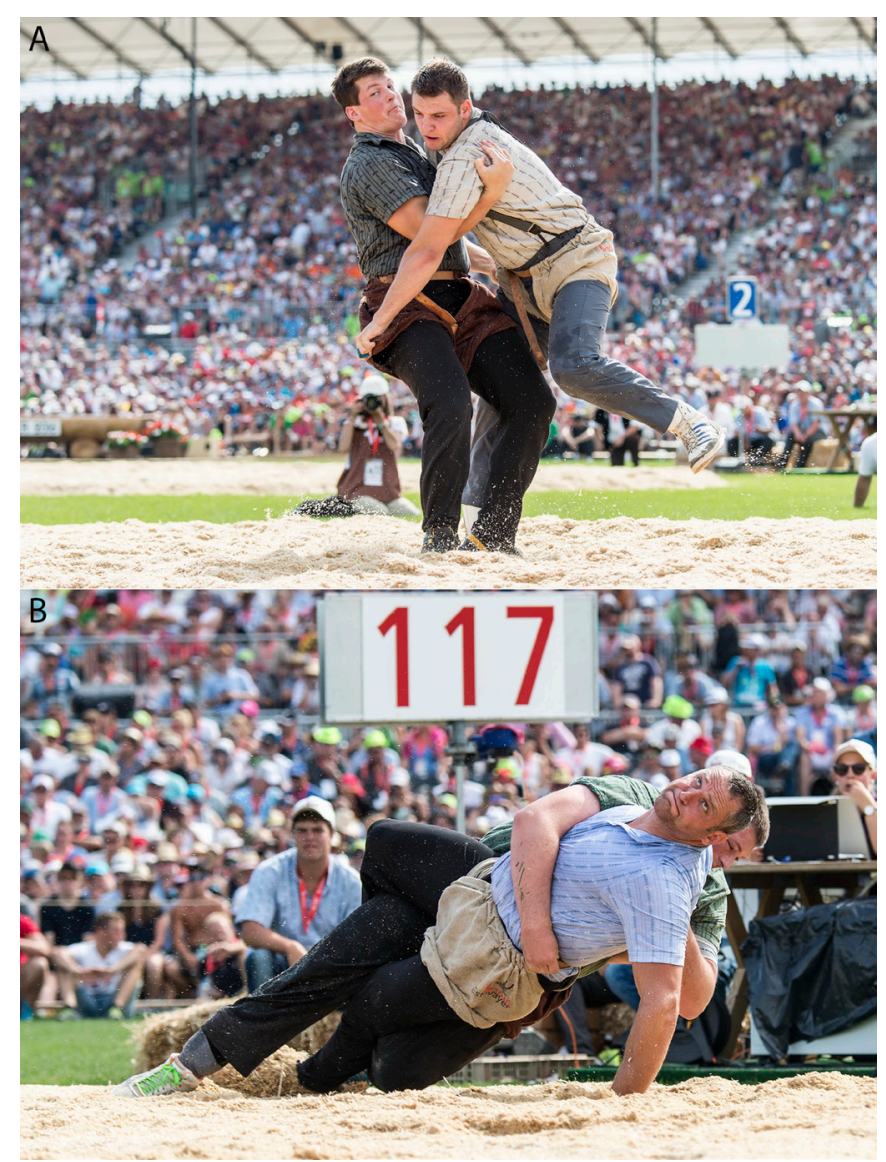

Figure 1 (A, B) Schwingen is a physical fight between two competitors and has its own rules, grips and throws. It is carried out on a circular sawdust padded surface.

professions that require physical strength, like carpenters, lumberjacks or cheesemakers.

Because of the wrestlers' strength and the absence of protective equipment, there is a risk of a wide variety of injuries. This study aimed to determine the incidence and risk from patients visiting our emergency department after Schwingen injuries. To the best of our knowledge, there has been no previous systematic review of Schwingen accidents. This is therefore the first in-depth study of injuries and injury patterns caused by Schwingen. Furthermore, the results should potentially prevent injuries.

\section{METHODS}

\section{Hospital unit and patient population}

The University Department of Emergency Medicine of the Inselspital Bern serves as a level I centre for patients older than 16 years, and commands a catchment area of 1.5 million people. It treats more than 45000 patients each year.

Our study was performed as a retrospective database query of all patients admitted to or initially treated in the emergency department from 1 January 2006 to 1 July 2016. The software used were Qualicare (Qualidoc, Trimbach, Switzerland) and E.Care (E.Care, Turnhout, Belgium). There was no restriction to active wrestlers. ${ }^{8}$
The database entries comprise basic demographic data as well as relevant historical details of medical symptoms or the type of accident. The database also provided the results of clinical consultations and examinations, together with medical and traumatological diagnoses and information on treatment after admission. The short-term outcome was defined by the type of care given to each patient (outpatient, inpatient, intermediate care unit (IMC), surgery or no surgery) and recorded as well.

\section{Data analysis}

The database entries comparise basic demographic data (age, gender), as well as relevant historical details of medical symptoms or the type of accident (injury type, injury area, mechanism of injury, route of admission to the hospital and treatment).

All calculations and graphs were performed with the Microsoft Excel spreadsheet.

\section{RESULTS}

\section{Sample analysis}

A total of 38 cases from 1 January 2006 to 1 July 2016 were initially identified as being related to Schwingen accidents. After rigorous inspection of each file, six patients were excluded from further analysis as they were found not to be related to Schwingen.

There was no definitive pattern regarding the year of admission (online supplementary figure 1a). Peak of admission took place in 2013, when 10 patients were admitted to the hospital. Although there is no statistically significant difference, it may be due to the fact that in 2013 the national Schwingen games took place, which means there were more bouts than normal. Admission was higher during spring and summer than in autumn and winter, presumably because there are fewer bouts in the colder seasons (online supplementary figure $1 b$ ). As regards the day of the week, 10 of 32 patients were admitted to the hospital on Sunday (online supplementary figure 1c). This may be because there were mostly more bouts on weekend.

The mean age of our patients was 24 years old. Twelve out of 32 patients were 20 years old or younger, 16 were 21-30 years old, while the remaining 4 patients were older than 30 years old. The youngest athlete was 16 and the oldest was 40 . Thirty-one of the 32 players were Swiss. The nationality of the remaining patient was not documented. Twenty-nine patients admitted to the hospital were men, plus a single woman. The gender of the remaining two patients was not documented. As regards the manner of admission to the hospital, 15 of the 32 patients came independently. Four were admitted from other smaller peripheral hospitals, four were admitted by ambulance and two were sent to the hospital by their family doctor. For the remaining seven patients, the manner of admission was not documented (online supplementary figure 2). Thirty-one of the patients were American Society of Anesthesiology Classification - ASA I (normal healthy individuals) and one patient was ASA II (patient with 
Table 1 Patient characteristics

\begin{tabular}{|c|c|c|c|c|c|}
\hline $\begin{array}{l}\text { Patient } \\
\text { number }\end{array}$ & Age & Cause of accidence & Diagnoses & Outcome & $\begin{array}{l}\text { Sick leave } \\
\text { duration }\end{array}$ \\
\hline 1 & 20 & Hit on the left cheek & Fracture of the left orbital floor & Surgery & 7 \\
\hline 2 & 26 & Rotation of the body upon the knee & Inner meniscus lesion & Medication & 10 \\
\hline 3 & 28 & Fall on the hand joint & Hand joint contusion & Medication & 4 \\
\hline 4 & 18 & Head injury after Schwingen training & Migraine, headache & Medication & 5 \\
\hline 5 & 21 & Fall on the back of the head & Spinal cord distortion & Medication & 0 \\
\hline 6 & 24 & Hit on the jaw & Jaw fracture & Surgery & - \\
\hline 7 & 16 & Fall on the head & Uncomplicated course & Medication & 0 \\
\hline 8 & 19 & Hit on the right side of the face & Jaw contusion & Medication & 0 \\
\hline 9 & 21 & Fall during Schwingen & Not dislocated collum fracture & Medication & 0 \\
\hline 10 & 40 & Hit on the face during Schwingen & Mandible fracture both sides & Surgery & 0 \\
\hline 11 & 26 & $\begin{array}{l}\text { Head reclination after fall on the } \\
\text { sawdust }\end{array}$ & Cervical spinal cord injury & Hospitalisation & 0 \\
\hline 12 & 19 & Fall during Schwingen & Fracture of the forearm & Surgery & 0 \\
\hline 13 & 22 & Fall on the right arm & $\begin{array}{l}\text { Recurrent dislocation of the left elbow, } \\
\text { fracture of the epicondylus lateralis, rupture } \\
\text { of the flexor pronatus muscle group }\end{array}$ & Surgery & 16 \\
\hline 14 & 22 & Opponent landed on his foot & $\begin{array}{l}\text { Isolated dislocation of the peroneus longus } \\
\text { muscle tendon of the right ankle }\end{array}$ & Surgery & - \\
\hline 15 & 18 & $\begin{array}{l}\text { Knocked down by opponent on the } \\
\text { left arm }\end{array}$ & $\begin{array}{l}\text { Fracture of left processus styloideus ulnaris, } \\
\text { fracture of the left processus styloideus } \\
\text { radialis }\end{array}$ & Plaster & 8 \\
\hline 16 & 27 & No known injuries during Schwingen & $\begin{array}{l}\text { Miller-Fisher syndrome, traumatic plexus } \\
\text { lesion }\end{array}$ & Hospitalisation & 0 \\
\hline 17 & 33 & Opponent walked upon him & Lisfranc fracture of the right foot & Surgery & 0 \\
\hline 18 & 28 & Rotation of the torso on a fixed foot & $\begin{array}{l}\text { Distortion of the knee, lesion of the } \\
\text { meniscus exterior }\end{array}$ & Medication & 0 \\
\hline 19 & 17 & Fall on the left shoulder & Shoulder contusion & Medication & 6 \\
\hline 20 & 26 & Hit on the left cheek & Contusion of left shoulder & Medication & 0 \\
\hline 21 & 20 & Direct hit on the nose & Upper ankle distortion & Medication & 4 \\
\hline 22 & 17 & Twisted ankle & $\begin{array}{l}\text { Distortion of the left knee, lesion of the } \\
\text { exterior band, lesion of ligamentum } \\
\text { cruciatum anterius }\end{array}$ & Medication & 0 \\
\hline 23 & 20 & $\begin{array}{l}\text { Foot injury on known valgus stress } \\
\text { background }\end{array}$ & Patient left hospital on his own decision & No treatment & 0 \\
\hline 24 & 22 & Fall on the back & $\begin{array}{l}\text { Tension of the apical dorsal thorax muscles, } \\
\text { hyposensibility digitus I-III }\end{array}$ & Medication & 4 \\
\hline 25 & 17 & Fall with his shoulder on the floor & Maisonneuve fracture of the right Malleolar & Surgery & 10 \\
\hline 26 & 17 & Foot injury & Shoulder contusion & Medication & 10 \\
\hline 27 & 31 & Opponent pulled his arm & Rips bruise & Medication & 0 \\
\hline 28 & 28 & Opponent felt on his torso & $\begin{array}{l}\text { Spontaneous vertebral artery dissection, } \\
\text { transient sensibility hemisyndrome on the } \\
\text { right side }\end{array}$ & Hospitalisation & 0 \\
\hline 29 & 29 & Rotation of the knee & $\begin{array}{l}\text { Rupture of the interior band, distortion of } \\
\text { the right knee }\end{array}$ & Plaster & 0 \\
\hline 30 & 32 & $\begin{array}{l}\text { Dorsal extension and abduction } \\
\text { trauma of the left arm }\end{array}$ & Injury of the sideband of the left thumb & Medication & 4 \\
\hline 31 & 29 & Rotation of the body on a fixed knee & $\begin{array}{l}\text { Rupture of the legantum crusiatum anterior, } \\
\text { injury of the left knee }\end{array}$ & Medication & 9 \\
\hline 32 & 24 & Fall on the left shoulder & Rockwood I injury of the left shoulder & Plaster & 2 \\
\hline
\end{tabular}




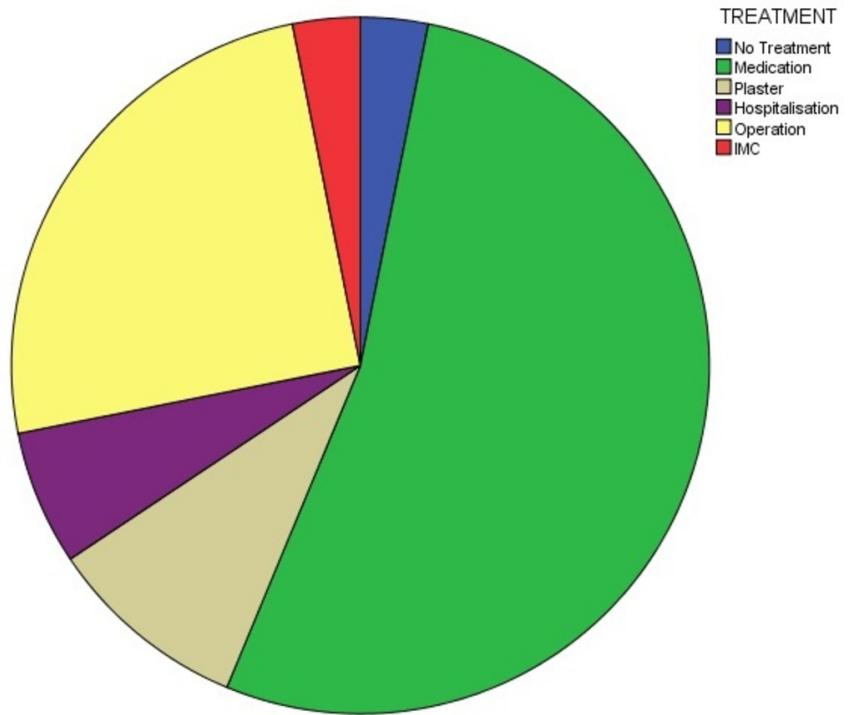

Figure 2 Treatment received by the patients for Schwingen accidents. IMC, intermediate care unit.

mild systemic disease). No shock-room alarm was activated for any of the 32 patients. The mean duration of sick leave was 3 days, while the greatest value was 16 days. This parameter was not documented for one patient due to insufficient data (table 1). Seventeen of the 32 patients were given medication such as analgesics and three patients were given a plaster. Two patients had to stay in hospital for further treatment while one patient was admitted to the IMC and eight patients had to undergo surgery. One patient decided to leave the hospital on his own accord, against medical advice (figure 2). Thirty-one of 32 patients were admitted for a single injury while one patient had multiple (double) injuries.

\section{Injuries and treatment}

The most commonly injured regions were the head $(n=10)$ and the knee $(n=5)$, followed by the shoulder, the hand/wrist and the foot/ankle, each with a frequency

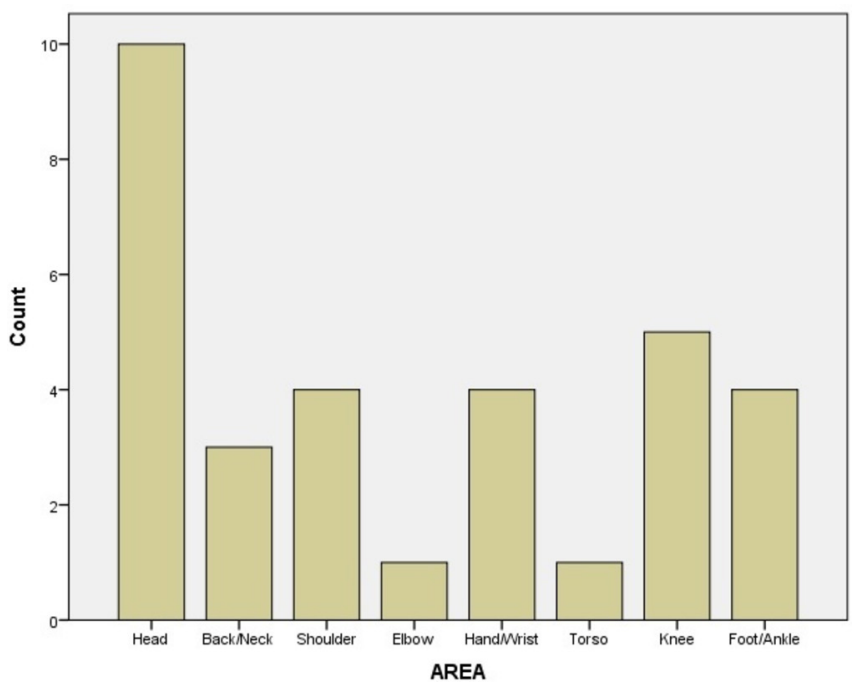

Figure 3 Area of injury of Schwingen accidents.

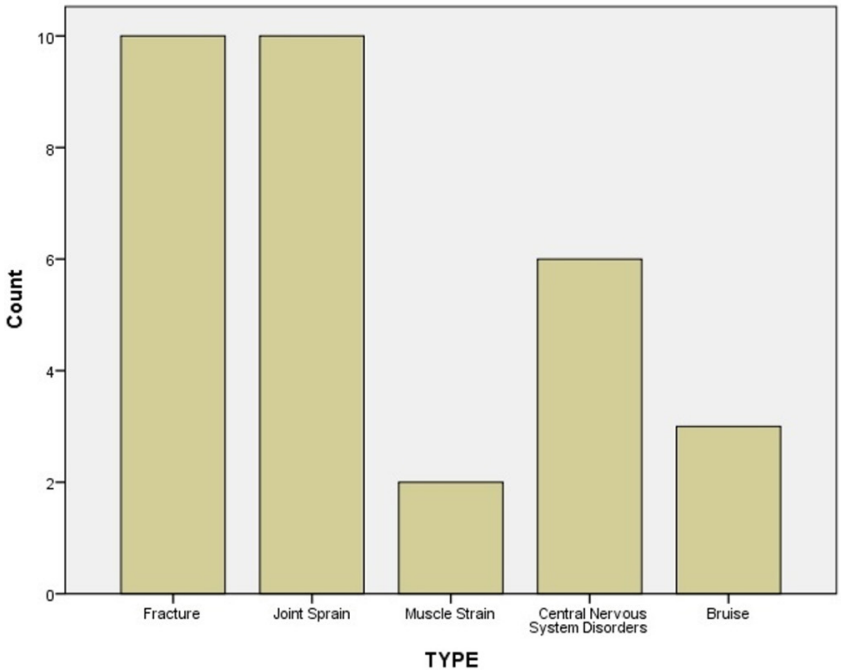

Figure 4 Type of injury of Schwingen accidents.

of 4/32 patients. Head injuries varied from simple uncomplicated headaches to contusions of the jaw joint and fractures of the head, such as mandible, jaw, nose and orbital floor fracture. On the other hand, the most common knee injuries were lesions and distortions (figure 3, table 1).

No catastrophic injuries or fatalities were encountered in our study population. The most common injury types were fractures $(n=10)$ and joint sprains $(n=10)$, followed by central nervous system disorders $(n=6)$, bruises $(n=3)$ and muscle strains $(n=2)$. For fractures, the most commonly injured area was the head (five patients), followed by the hand/wrist (two patients) and the foot/ ankle (two patients). Joint sprains were most often in the knee and the shoulder. Central nervous system disorders ranged from simple headaches due to head trauma, to spinal cord injuries, vertebral artery dissection and the Miller-Fisher syndrome (figure 4).

The most common mechanisms of injury were falls $(n=11)$ and direct force/blows $(n=10)$. This was followed by twisting/stretching $(\mathrm{n}=7)$, while for the remaining four patients, the mechanism of injury is unknown. It was not possible to determine the exact specific wrestling moves that caused injury because of inconsistency in the reporting of the manoeuvres. In addition, many of the injuries were not the result of specific wrestling moves but rather the individual wrestling situation. No injuries were specifically reported as having been caused by illegal actions, although the injuries were not described in detail (figure 5).

In our study, two of the 32 patients were diagnosed with a cervical spinal cord injury. Athletic injuries to the cervical spine resulting in damage to the spinal cord are infrequent—but catastrophic-events. ${ }^{9}$ Thankfully, cervical spinal cord injuries associated with wrestling are relatively rare. ${ }^{10-12}$ The patients in our study recovered without long-term effects. One of the patients in our emergency department was diagnosed as having vertebral artery dissection. This patient recovered without 


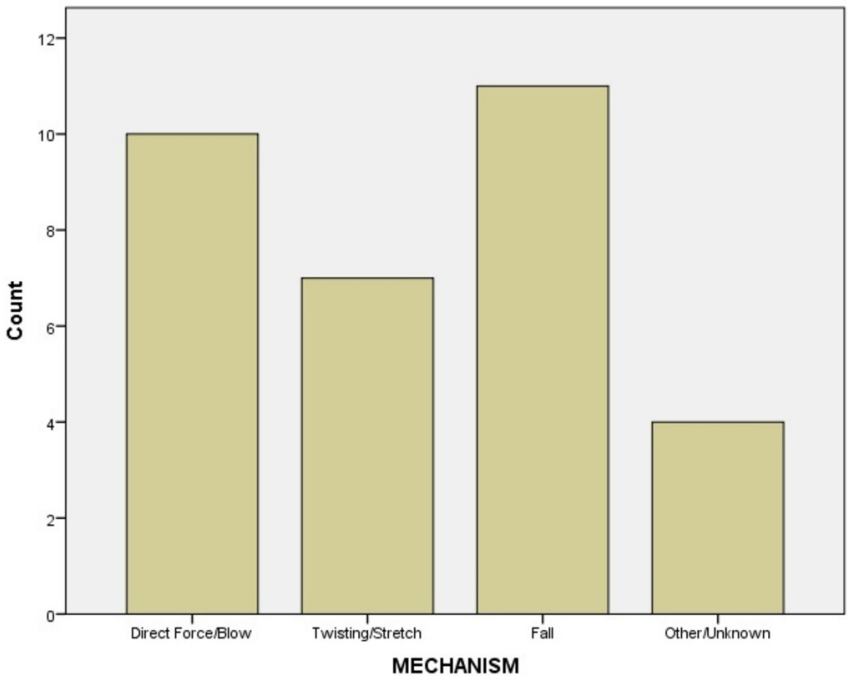

Figure 5 Mechanism of injury of Schwingen accidents.

long-term effects. One of the patients was admitted to our emergency department with the diagnosis of possible Miller-Fisher syndrome. He recovered without long-term effects.

\section{DISCUSSION}

Schwingen is a sport which needs healthy, strong participants. The athletes who are going to compete must be well trained-both physically and mentally. ${ }^{13}$ Any sport which involves falling necessarily involves the risk of injury. In any takedown at least one wrestler is not in control of the situation and sometimes neither wrestler is in control. Furthermore, it is open to competitors of all sizes. There is a definite injury problem associated with the sport, and it has been the purpose of our paper to present the common injuries and to discuss their prevention.

\section{Severity of injuries}

Our findings regarding the severity of injuries seem to agree with Jarret et $a l^{14}$ who did not document any catastrophic or fatal injuries. Boden et $a l,{ }^{10}$ on the other side, reported 2.11 catastrophic injuries pro 100.000 injuries. Agel et $a l^{15}$ have described a ratio of approximately $30 \%$ of severe injuries (more than 10 days' recovery period).

Jarret et $a l^{14}$ report the 'takedown' as the most common mechanism of injury and Agel et $a l^{15}$ the 'player contact'. We have found that the fall was the most common injury mechanism. However, we did not have the necessary data to describe the exact position, grip or situation related to the injuries.

Requa and Garrick ${ }^{16}$ agree with our findings and reported sprains and strains as the most common types of injuries $(75 \%)$. Pappas $^{17}$ reports sprains/strains $(36.5 \%)$ and fractures $(21.3 \%)$ and Jarret et $a l^{14}$ report sprain, strains and contusions.

We have found that the head is the body area with the highest injury ratio; in contrast, Requa and Garrick ${ }^{16}$ reported that most injuries were in the spine and the trunk
$(34 \%)$, followed by the lower $(33 \%)$ and upper (29\%) extremities. Pappas ${ }^{17}$ found that the upper extremities $(44.3 \%)$ were the area of the body with the highest injury frequency, followed by the lower extremities $(20.5 \%)$ and the head (16.9\%), while Agel et $a l^{15}$ found that the lower extremities were the most commonly injured body area, followed by the upper extremities and the head. On the other hand, Pasque and Hewett ${ }^{18}$ found that most injuries were in the shoulder $(24 \%)$ and the knee $(17 \%)$.

\section{Neurological disorders}

Falling to the floor in a twisted position or unaccepted holds were thought to account for cervical spine and cord injuries, which was the case in two of our patients. The head is also involved in these injuries, when it strikes the ground, although this is secondary to the cervical spine. The cervical spine can be injured in the following ways: hyperflexion injury, hyperextension, lateral flexion, axial loading and rotational forces. Cervical spinal stenosis can also predispose to cervical spine injury. ${ }^{19}$ The anatomy of the cervical spine makes little sense, considering that it is one of the most delicate structures of the body and yet has little protection. This leaves the area susceptible to injuries. Both patients recovered without long-term effects.

One of our patients was diagnosed with a vertebral artery dissection. This rare injury is reported in 1\%-2\% of blunt injuries to the neck. The close anatomical relationship between vertebral arteries and cervical vertebrae makes it likely that dislocating spinal injuries may cause stenosis or occlusion of one or both of these arteries. The vertebral artery is extremely vulnerable to torsion injury because it winds around the atlas to enter the skull; any abrupt rotation may stretch the artery and tear the delicate intima. Thrombosis formed over this vascular injury may subsequently be dislodged and may embolise to the brain. This is probably the most frequent cause of stroke in these patients and produces a characteristic angiographic appearance-sometimes with 'false' aneurysms. Less frequently, the vessel may be occluded by a collar of haematoma forming in the vessel wall at the site of the dissection. ${ }^{20}$ Neck pain is a reliable symptom of the onset of dissection, followed a variable time later by neurological deficits caused by blood splitting the arterial wall after the intimal tear. Cervical artery dissection is a significant cause of carotidynia. ${ }^{20}$ Vertebral artery dissection has been reported for a sumo wrestler. ${ }^{21}$

One patient was suspected to be suffering from the Miller-Fisher syndrome. This is a polyneuropathy with benign outcome characterised by ophthalmoplegia, limb ataxia and tendon areflexia. This has not been previously reported in wrestlers. ${ }^{22}$

\section{Protective gear}

Injuries due to direct forces or falls will probably never be completely eliminated from Schwingen. By examining how injuries occur, we can gain insight into their prevention. Wearing headgear is currently not mandatory 
for most competitions. Absence of headgear has proven a risk factor in sustaining-for example-auricular haematoma in other wrestling sports. Headgear could offer protection from some types of injuries. ${ }^{23}$ It is recommended that headgear should have a sufficient number of straps to fix it firmly on the head and with deep enough earpieces so that there is no contact between the ear itself and the headgear. A 1/4-1/2 thick high-density foam 'doughnut' is sometimes added around the earpiece to further increase its depth. ${ }^{22}$

Mouthguards have never been a standard piece of equipment for wrestlers worldwide. Several reasons are given for not wearing mouthguards, including poor retention secondary to fit, discomfort and interference with breathing or speech. ${ }^{24}$ Well-fitted mouthguards during practice and competition may prevent irreversible dental injury. Wrestlers suffer more dental injuries than controls. ${ }^{25}$

The role of knee pads and shoes has not been evaluated, but in other sports they have been effective in preventing injuries.

\section{Further protective measures}

Schwingen is an amateur sport. Many wrestlers are inexperienced and must bear in mind that close attention to proper technique is essential for a safe competition. Teaching sessions could be established for players, coaches and other officials in order to make them aware of the possibility of fatal injuries. For example, it could be beneficial if the trainers teach wrestlers to keep their heads up during takedowns, to avoid axial compression or flexion of the spine that can lead to serious injury. ${ }^{1126}$

Better attention by wrestling officials to infractions of the rules and dangerous moves can also be crucial in preventing serious injury. A solid, aggressive wrestling match is a safe athletic event as long as the referee is able to control the match and prevent volatile tempers from getting out of hand. ${ }^{24}$ The judge must guard against the misuse of protective and other equipment such as helmet, cervical collar or the clothes of the Schwinger. He must be aware of illegal or potentially dangerous grips and throws and know how to anticipate them.

Schwingen is carried out mainly by strong young male athletes. If these competitors call for medical advice or withdraw from the wrestling pit, they may be facing really major health problems. However, for many injuries, clinical symptoms appear only after a period of time when it is already late for state-of-the-art medical treatment. This is why it is important to recognise the signs early and to manage the symptoms appropriately. An athletics trainer should be present at all practices and competitions, and the match physician at all competitions. ${ }^{24}$ It would be of great value if physicians with a keen interest in Schwingen were always present during the great tournaments and ideally during the training sessions. It is essential to have an appropriate healthcare system in place prior to the start of the season.
Athletes who are going to compete must be in an optimum state of health. Several studies have found that prior injury predisposes an athlete to new injury. ${ }^{167-29}$ This is exactly the reason why all athletes should undergo a preseason full health check-up. Prior to the start of the games, all athletes should undergo a preparticipation physical examination, including orthopaedic screening. Participants with complaints of tingling, numbness or local muscle atrophy or seizures must be thoroughly investigated. It could also be useful to perform a preparticipation radiological control of the cervical spine, for comparison following any trauma, and to identify individuals with evidence of previous osteoarticular injury. ${ }^{25}$ Individuals with long necks, poor neck musculature, or those with congenital abnormalities of cervical spine should be watched carefully. ${ }^{26}$ After repeated episodes of trauma, careful and thorough evaluation must also be made. For other versions of wrestling, such as college wrestling, proposals have already been made for treatment protocols and strict guidelines for return to competition following injury. ${ }^{30}$ An adequate ring surface area can lead to the avoidance of many injuries, especially during training. According to several studies, ${ }^{11}$ at least 100 square feet per wrestling pair has proven enough to reduce injuries. Larger practice areas prevent pairs of wrestlers from rolling into each other or falling on other objects and being injured. If we are to preserve the traditional characteristics of the sport, the maximum permitted diameter of the ring, approximately $14 \mathrm{~m}$, should be employed.

Minor orthopaedic injuries and fatal neurological disorders may be reduced with optimal material for the surface of the ring. It could be of great value if the fight was carried out on a high-quality professional wrestling mat, which is already the case in other contact sports. In order once more to preserve the traditional character of the sport, the surface of the wrestling mat could be totally covered with the traditional sawdust so that it looks exactly the same as the beloved Schwingen ring.

Contributor NKM, JK-R, TCS, BL, GK, AKE contributed in the data analysis and preparation of this manuscript.

\section{Competing interests None declared.}

Open Access This is an Open Access article distributed in accordance with the Creative Commons Attribution Non Commercial (CC BY-NC 4.0) license, which permits others to distribute, remix, adapt, build upon this work non-commercially, and license their derivative works on different terms, provided the original work is properly cited and the use is non-commercial. See: http://creativecommons.org/ licenses/by-nc/4.0/

(C) Article author(s) (or their employer(s) unless otherwise stated in the text of the article) 2018. All rights reserved. No commercial use is permitted unless otherwise expressly granted.

\section{REFERENCES}

1. Renggli TS. Vom hosenlupf zum spitzensport: ein schweizer phänomen. Lenzburg: Fona Verlag AG, 2013.

2. Eidgenössischer Schwingerverb and association federale de luttle suisse. Modernes leitbild gibt die richtung vor. (retrieved 30 Mar 2014).

3. Schwingen - Ring Sport Verband Vorarlberg. https://www.rsvv.at/ schwingen/ 
4. Eidgenössischer Schwingerverband. https://esv.ch/schwingen/ hauptschwuenge/

5. Schwingermuseum Winterthur. esv.ch - Eidgenössischer Schwingerverband. https://esv.ch/schwingen/kampfgericht/

6. Eidgenössischer Schwingerverband From. Die benotung imsagemehl. https://esv.ch/schwingen/benotung/

7. Watson. Schwingen: dank diesem crashkurs beim eidgenössischen mitreden. www.watson.ch

8. Nakagawa Y, Minami K, Arai T, et al. Cervical spinal cord injury in sumo wrestling: a case report. Am J Sports Med 2004;32:1054-8.

9. Darrow CJ, Collins CL, Yard EE, et al. Epidemiology of severe injuries among United States high school athletes: 2005-2007. Am J Sports Med 2009;37:1798-805.

10. Boden BP, Lin W, Young M, et al. Catastrophic injuries in wrestlers. Am J Sports Med 2002;30:791-5.

11. Snook GA. The injury problem in wrestling. Am J Sports Med 1976;4:184-8.

12. Açikgöz B, Ozgen T, Erbengi A, et al. Wrestling causing paraplegia. Paraplegia 1990;28:265-8.

13. Rich V, McCaslin E. Central cord syndrome in a high school wrestler: a case report. J Athl Train 2006;41:341-4.

14. Jarret GJ, Orwin JF, Dick RW. Injuries in collegiate wrestling. Am J Sports Med 1998;26:674-80.

15. Agel J, Ransone J, Dick R, et al. Descriptive epidemiology of collegiate men's wrestling injuries: national collegiate athletic association injury surveillance system, 1988-1989 through 20032004. J Athl Train 2007;42:303-10.

16. Requa R, Garrick JG. Injuries in interscholastic wrestling. Phys Sportsmed 1981:9:44-51.

17. Pappas E. 'Boxing, wrestling, and martial arts related injuries treated in emergency departments in the United States, 2002-2005'. J Sports Sci Med 2007;2:58-61.
18. Pasque CB, Hewett TE. A prospective study of high school wrestling injuries. Am J Sports Med 2000;28:509-15.

19. Norris JW, Beletsky V, Nadareishvili ZG. Sudden neck movement and cervical artery dissection. CMAJ 2000;163:38-40.

20. Osawa A, Maeshima S, Maruyama H, et al. Late-onset dysphagia in a sumo wrestler after a sumo bout. Curr Sports Med Rep 2013;12:11-13.

21. Pulitanò S, Viola L, Genovese O, et al. Miller-Fisher syndrome mimicking intracranial hypertension following head trauma. Childs Nerv Syst 2005;21:473-6.

22. Schuller DE, Dankle SK, Martin M, et al. Auricular injury and the use of headgear in wrestlers. Arch Otolaryngol Head Neck Surg 1989;115:714-7.

23. Hewett TE, Pasque C, Heyl R, et al. Wrestling Injuries. Epidemiology of pediatric sports injuries basel: KARGER, 2005:152-78.

24. Persson LG, Kiliaridis S. Dental injuries, temporomandibular disorders, and caries in wrestlers. Scand J Dent Res 1994;102:367-71.

25. Puggelli J. Integrating freestyle and Grec-Roman techniques (part 2): prevention of injuries. Scholastic Coach 1981;50:94.

26. Kewalramani LS, Krauss JF. Cervical spine injuries resulting from collision sports. Paraplegia 1981;19:303-12.

27. Estwanik JJ, Bergfeld J, Canty T. Report of injuries sustained during the United States Olympic wrestling trials. Am J Sports Med 1978;6:335-40.

28. Strauss $\mathrm{RH}$, Lanese RR. "Injuries among wrestlers in school and college tournaments.". Jama 1982;16:2016-9.

29. Wroble RR, Mysnyk MC, Foster DT, et al. Patterns of knee injuries in wrestling: a six year study. Am J Sports Med 1986;14:55-66.

30. Wroble RR. Wrestling. In: Combat sports medicine. London: Springer London, 2009:215-45. 